\title{
INTERFERÊNCIAS DE CONJUNTOS HABITACIONAIS NA PAISAGEM DE BELO HORIZONTE - O CASO DO GOIÂNIA
}

\author{
INTERFERENCES OF HOUSING SETTLEMENTS IN BELO HORIZONTE LANDSCAPE - THE \\ CASE OF GOIÂNIA
}

\author{
TEIXEIRA, Maria Cristina Villefort \\ Arquiteta. Doutora em Planejamento Urbano (IPPUR/UFMG). Professora da Escola de Arquitetura/ UFMG- \\ Departamento de Projetos. E-mail: mcrisvt@gmail.com
}

\section{RESUMO}

Os projetos de conjuntos habitacionais têm sido elaborados por profissionais competentes, cujo propósito é o de assentar famílias de baixa renda, em condições adequadas, com o menor custo possível. Ao serem ocupadas por seus moradores, essas casas passam por transformações dos mais variados aspectos, que vão das interferências internas até ao comprometimento da paisagem de todo o assentamento. Projetos que aparentemente são pensados e concebidos para atender com qualidade a essa demanda não vêm sendo apropriados por seus moradores conforme o estabelecido. Os objetivos do presente trabalho são analisar quais fatores provocam tais transformações na paisagem local, além de verificar aqueles que podem contribuir para que esse atendimento às camadas menos favorecidas se torne mais eficaz.

\section{Palavras-chave: Conjunto habitacional, paisagem, transformação.}

\begin{abstract}
The projects of the housing settlement have been elaborated by competent professionals, which purpose is to install low income families, under proper conditions, with the lowest cost possible. By the time those houses are occupied, they pass through many aspects of transformations that go from inner interferences to commitment of landscape. Projects that apparently are thought and made to support this supply in quality are not being appropriated by their users as it was thought. The present work aims are to analyze the points that produced the local landscape transformations, besides to verify those who can contribute to attend the less wealthy people.
\end{abstract}

Key words: Residential settlement, landscape, transformation.

\section{Introdução}

No início de sua atuação, nos anos 90, a Companhia Urbanizadora de Belo Horizonte (URBEL) implantou cinco conjuntos habitacionais na cidade, para assentar o enorme contingente de famílias atingidas pelas chuvas. Com o propósito de aplicar as novas diretrizes impostas pela municipalização da política habitacional, esses conjuntos foram construídos em bairros consolidados, munidos de infra-estrutura e equipamentos urbanos e com a participação efetiva dos envolvidos na produção da moradia. O conjunto Goiânia, localizado no setor nordeste da cidade, bem ilustra esse exemplo e, no caso específico, o bairro que o envolve atende a esses requisitos, sendo que grande parte de seus moradores pertence à classe média.

Os projetos das moradias do conjunto a ser implantado deveriam ser construídos em duas etapas, sendo que a URBEL se responsabilizaria pela construção do primeiro pavimento. A ampliação posterior da casa caberia ao morador, que deveria executá-la de acordo com o projeto oferecido pelo órgão, que destinava os acréscimos ao segundo pavimento. 
Porém, ao se apropriarem de suas moradias, os usuários dos conjuntos, na maioria, não obedeceram aos parâmetros ditados previamente pelo poder público: ampliaram a casa horizontalmente, ocuparam o lote em quase toda a sua extensão e não construíram o segundo pavimento conforme foi estabelecido no projeto. Ao mesmo tempo, as moradias modificadas permaneceram com suas fachadas no esqueleto, não apresentaram acabamento conforme o estabelecido pela URBEL, implicando no acentuado contraste com as demais residências do bairro, que apresentavam padrão construtivo elevado. Quais os efeitos da implantação de um conjunto dessa natureza na paisagem local, que até então se aproximava na sua "homogeneidade"?

\section{A paisagem}

Santos afirma que a configuração territorial e a dinâmica social são dois componentes que interagem continuamente nos espaços urbanos (1997, p.111). Para ele, a configuração territorial se dá pelo arranjo sobre o território dos elementos naturais e artificiais de uso social, ao passo que a dinâmica social diz respeito ao conjunto de variáveis econômicas, culturais e políticas, que a cada momento histórico dão uma significação e um valor específicos ao meio técnico criado pelo homem, ou seja, à configuração territorial.

Assim, a paisagem do bairro antes da implantação do conjunto Goiânia se mantinha dentro de certo padrão homogêneo, apesar de haver diferenciações entre as casas e as pessoas. Afinal, como se considera no senso comum, "cada casa é um caso". De fato, as diferenças físicas e sociais se ajustavam e, ao longo do tempo do estabelecimento dos indivíduos no local, tais diferenças se tornaram imperceptíveis nas suas relações cotidianas.

No contexto urbano, essas residências se constituíam, na maioria, de dois pavimentos, tinham garagem para abrigar dois carros e jardim frontal. A varanda, elemento fundamental na moradia mineira, servia de transição do espaço público para o interior da casa, onde eram dispostos móveis que possibilitavam a permanência da família ali nos momentos de lazer. A grade sugeria a permeabilidade necessária para que se realizassem as relações de vizinhança, sem que, no entanto, os habitantes da casa se sentissem destituídos da sua privacidade. Na verdade, essas casas traduziam o ideário da classe média no que dizia respeito às condições de consumo.

\section{O projeto}

O projeto do conjunto Goiânia foi elaborado por um escritório de arquitetura cadastrado na URBEL e obedeceu a normas ditadas pela Lei de Uso e Ocupação do Solo. A sua aprovação prévia na Prefeitura comprova o atendimento às condições de conforto e às características mínimas de dimensionamento da legislação.

Foram implantadas 42 casas, destinadas a famílias oriundas de áreas de risco, que compreendiam o lote com o seu respectivo quintal, não sendo previsto no projeto original o fechamento com muro individualizado. Isso tornaria o custo da obra mais elevado e poderia fugir da proposta do conjunto, que seria a de integrar as edificações entre si.

No centro do Goiânia foi prevista uma pequena área de lazer, onde as crianças poderiam brincar em segurança. Além de promover encontros dessa população, a pracinha se destinaria a elemento de articulação com o bairro, pois ela se abria para a avenida.

A volumetria do conjunto deveria formar blocos diferenciados que seguiriam a direção dos eixos longitudinais, quebrados pela movimentação dos telhados dispostos contra a topografia e pelo agrupamento de casas com cores diferentes, o que tornava seu aspecto peculiar e permitia maior diversidade na paisagem. 


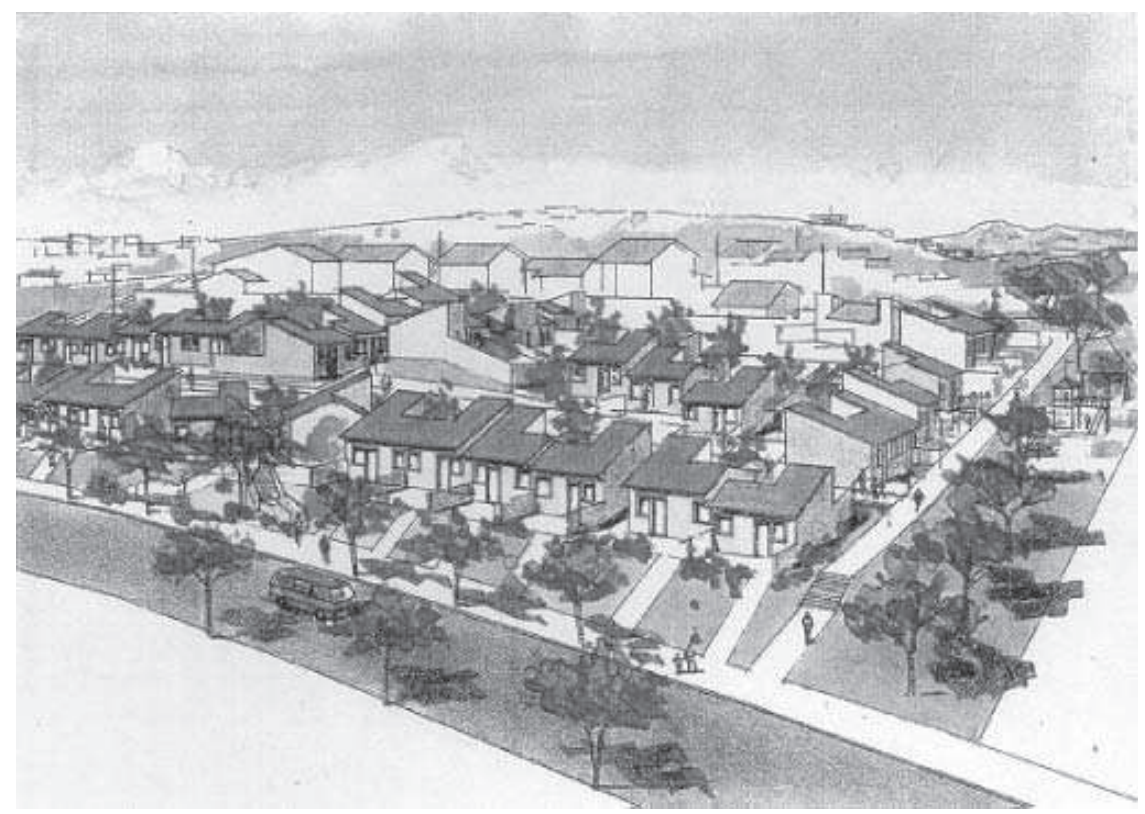

Figura 1: O Conjunto Goiânia idealizado pela autora Crédito: Elaborado por Ana Schmidt

Como se nota, a autora procurou atender às especificações que Silva (1983, p.37) considera como prioritárias para a boa ação projetual, ou seja, uma solução para um particular problema de organização do entorno humano, em que se determina certa forma construtível, através da descrição dessa forma e das prescrições para a sua execução. $\bigcirc$ projeto apreendeu as condições estabelecidas por normas técnicas e construtivas, ao proporcionar no espaço a ser vivido salubridade, conforto e bem estar ao usuário, embora, infelizmente, a participação desse grupo no processo de elaboração tivesse se restringido à sua apresentação para a comunidade. Apesar de Além disso, sua implantação seria integrada aos condicionantes do terreno, implicando em interferências mínimas na paisagem local.

\section{A nova paisagem}

Apesar de se buscar nos projetos melhor adequação às condições locais, houve modificações nas residências, a partir da sua ocupação. À medida que o espaço projetado passou a ser vivenciado pelos novos habitantes, novas interferências foram acontecendo na sua configuração física, conseqüência dos valores e da experiência dessa comunidade, que também se refletiram no lugar através do caráter simbólico da posse da casa.

De acordo com Macedo (1999, p.11), a paisagem é "a expressão morfológica das diferentes formas de ocupação e, portanto, de transformação do ambiente em um determinado tempo".

De fato, as alterações recorrentes no processo de adaptação indicaram que as condições originais das habitações eram insatisfatórias para os seus usuários e, à medida que as pessoas iam vivenciando o novo espaço, elas puderam perceber a melhor maneira de adaptá-lo às suas necessidades. Assim que as condições financeiras permitiam, eram feitas modificações na proposta original. Essas modificações traduziam tanto a adequação do espaço físico para melhor acomodação dos moradores, como a necessidade de representar a singularidade da vida de cada família.

O desejo de tomar posse da propriedade, garantindo privacidade e segurança, levou grande parte dos moradores dos conjuntos à providência inicial de construção de muros para fechar seus lotes. Conforme avalia Teixeira (2004, p.71), essa tendência foi confirmada como a principal 
interferência nas novas moradias e, conseqüentemente, na paisagem. Também a ampliação e o acréscimo de novos cômodos, especialmente quartos, áreas de serviço, varandas, garagens, escadas ou cozinhas externas foram modificações significativas que comprometeram as fachadas do conjunto. Esses novos espaços foram incorporados gradualmente ao corpo da casa, ampliando a área construída e diminuindo o quintal e, como elas se deram simultaneamente e sem qualquer preocupação com o acabamento, apresentando diferenciações mais significativas na paisagem até então ali estabelecida.

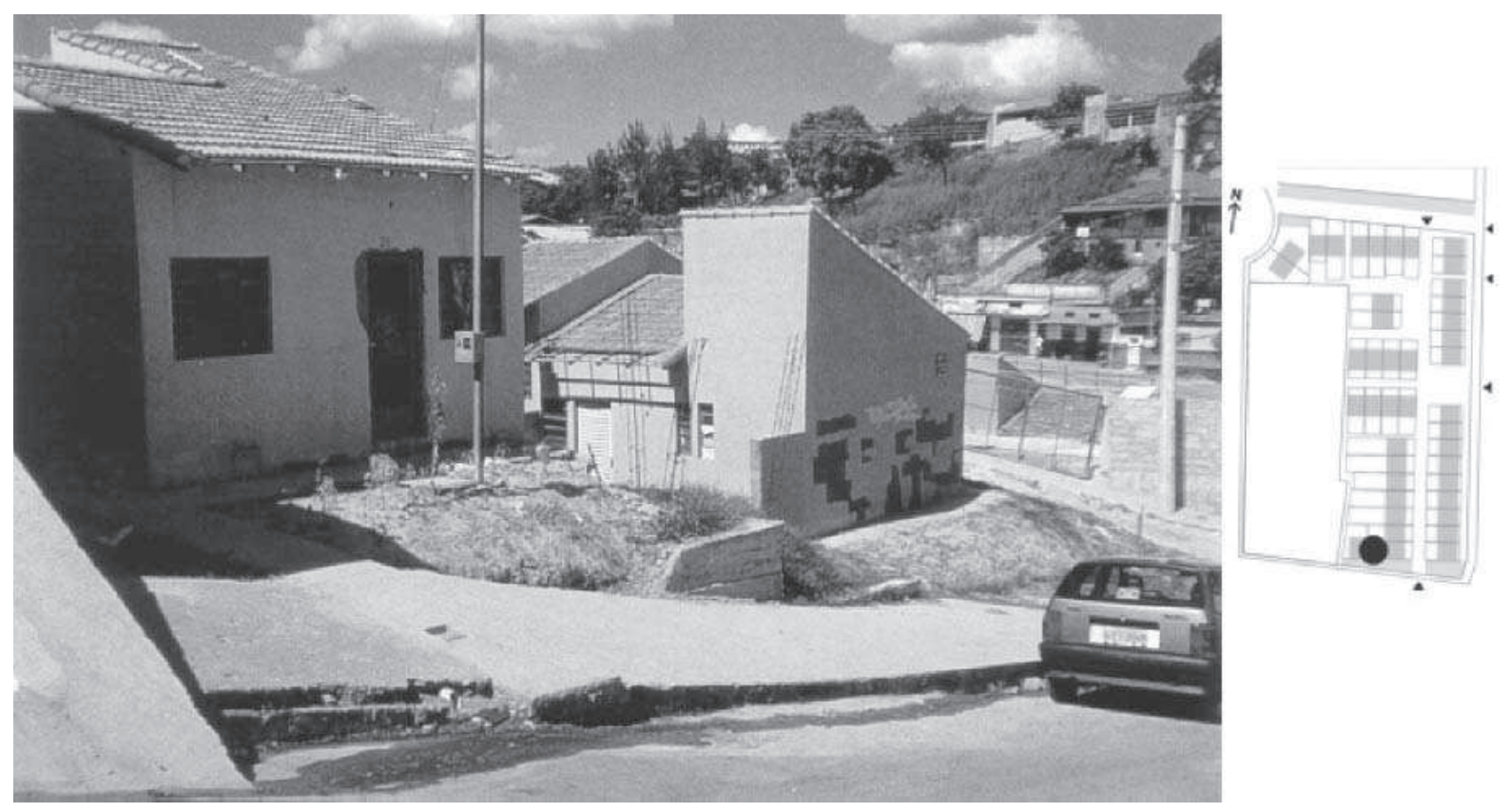

Figura 2: Foto da construção por etapas do Conjunto Goiânia (1998) Crédito: Foto de NASCIMENTO, 1998

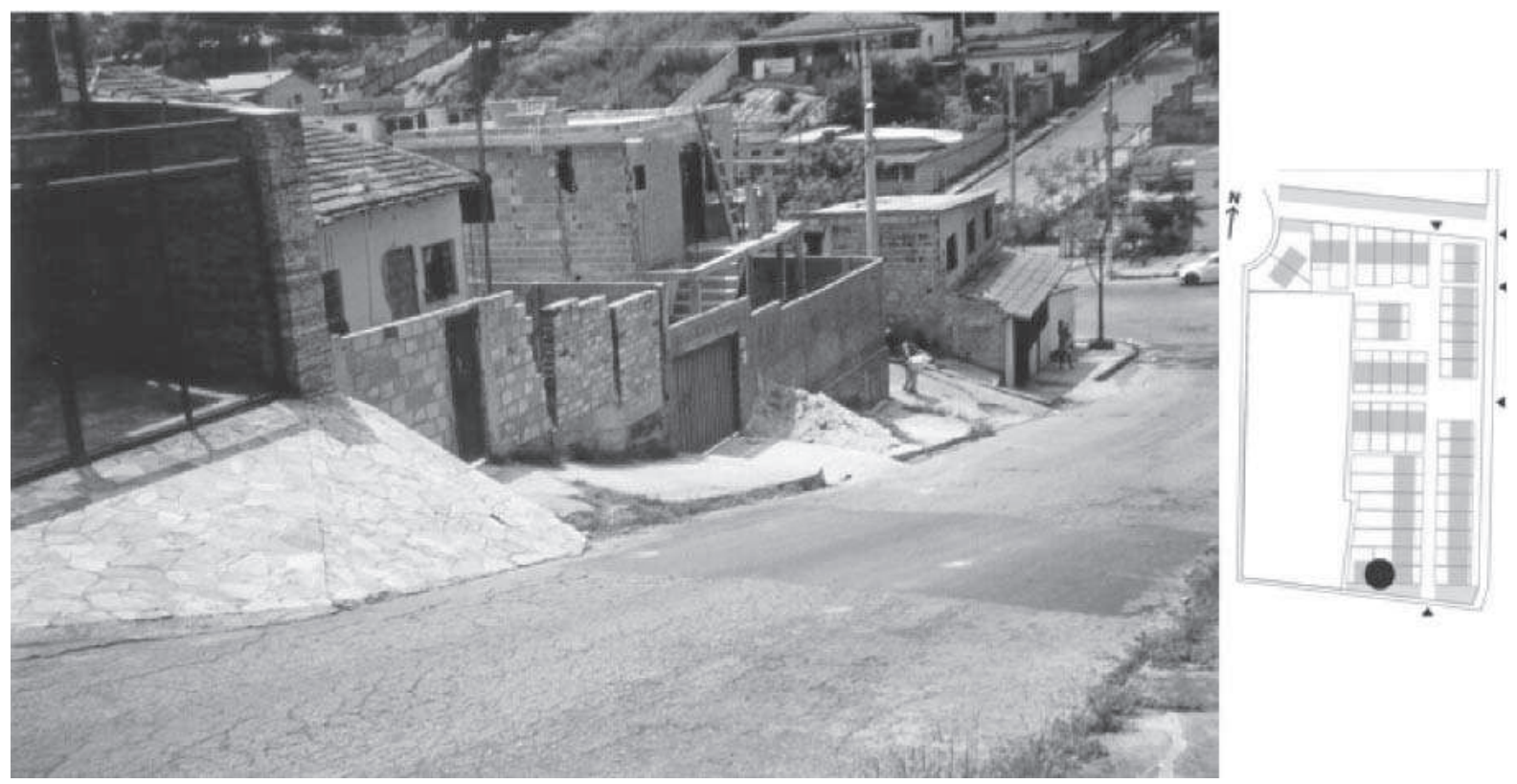

Figura 3: Foto da construção por etapas do Conjunto Goiânia (2003)

Crédito: Acervo particular da autora 
Além disso, em alguns casos, lugares destinados ao uso coletivo, que permitiam encontros dos moradores nas suas relações de vizinhança, foram invadidos, tornando privado o espaço público. Como exemplo, a citada praça foi apropriada, tornando-se parte do quintal da casa anexa. Outro exemplo de uso indevido do espaço público foi a instalação de um ferro velho numa das casas, cujo proprietário acumulava todo o material usado no local destinado ao lazer dos habitantes do conjunto.

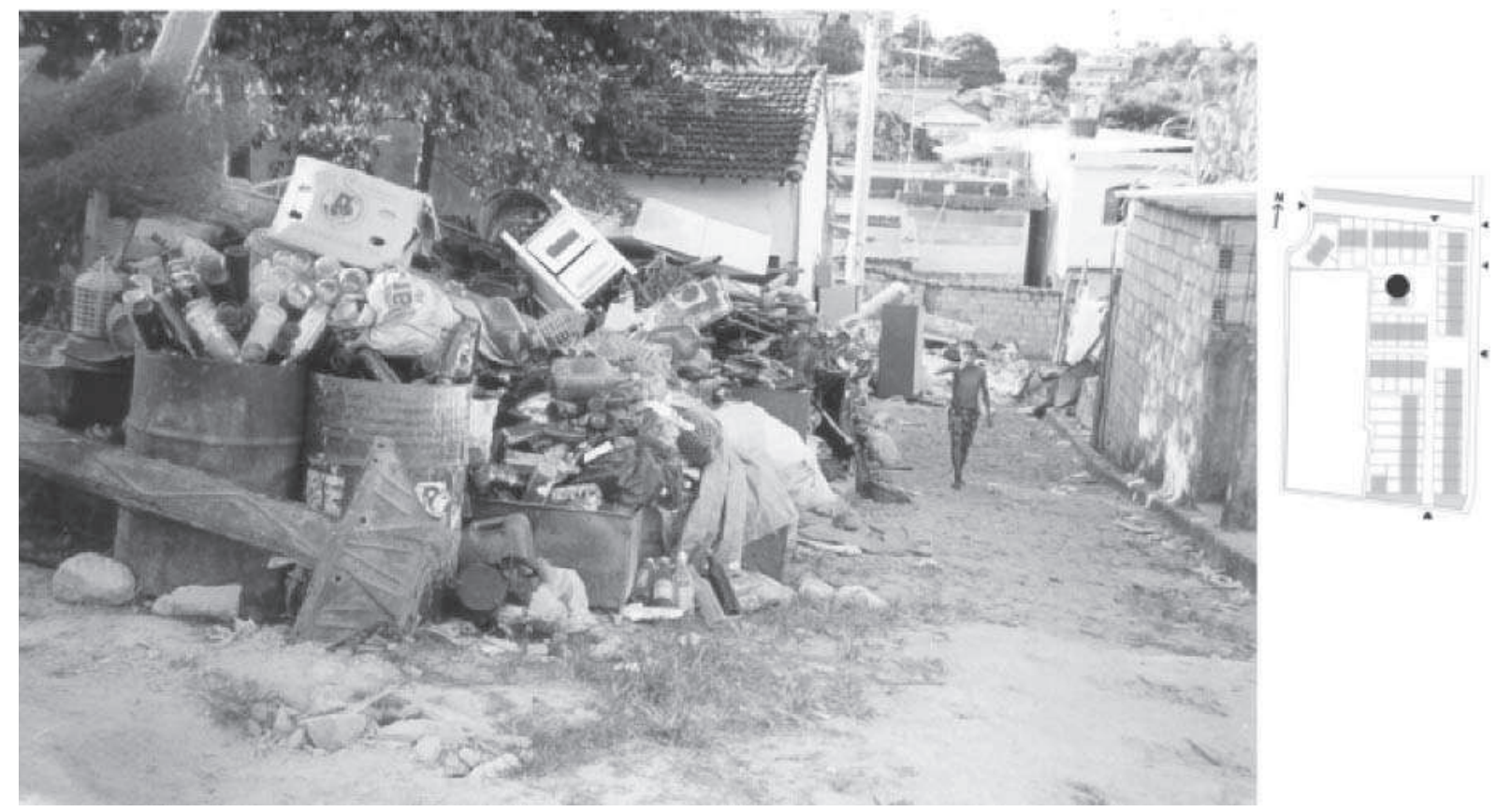

Figura 4: Vista do ferro velho do conjunto

Crédito: Acervo particular da autora

Por outro lado, não havia no Goiânia uma liderança que proporcionasse a todos os seus habitantes a oportunidade de se unir contra essas ações; havia manifestações individuais, mas não tinham força para serem argumentadas na esfera coletiva.

Das alterações constantes na maioria das residências ocorrem não só danos à qualidade arquitetônica das casas, como também ao comprometimento do aspecto geral da paisagem local. Evidencia-se, assim, nossa preocupação em demonstrar tudo quanto de danoso pode resultar de um projeto imposto, que não leva em consideração aspirações naturais dos futuros usuários, como demonstra a foto desse projeto na realidade.

Este fato nos lembra Santos (1985, p.7), ao afirmar que, em geral, os resultados da atividade do cientista, do planejador, do administrador, do técnico, do político sobre as cidades começam quando toda essa gente sai de cena. Quando os seus projetos deixam de ser mapas, memoriais, orçamentos, leis, decretos ou planos financeiros e se transformam em uma linguagem física decodificável no dia-a-dia. O autor afirma com muita propriedade que, infelizmente, é neste momento inicial crítico que os trabalhos urbanísticos são dados por terminados e, "na verdade estão é começando, passando das abstrações estáticas às práticas sociais contaminadoras e cambiantes que caracterizam o que é urbano".

O desenfreado acréscimo, com tamanha interferência na paisagem, passou a incomodar os antigos moradores, que viam no conjunto Goiânia o oposto que desejariam na sua vizinhança. Pôde-se notar que as manifestações não se deram só no campo físico, mas também no social. Este fato motivou a condenação veemente de vários entrevistados que moravam no entorno do 
conjunto, como por exemplo: "Tenho vontade de mudar daqui, sem me referir a essa pobreza. O conjunto incomoda. Ele é feio e sujo". O conjunto passou a ser visto pelos antigos moradores como elemento externo à paisagem, como se não fizesse parte de um todo. E visto de maneira negativa, sem qualquer vinculação com o todo.

O estranhamento do grupo ali instalado anteriormente foi fator novo na implantação de conjuntos habitacionais, pois antes da municipalização das políticas habitacionais esses assentamentos se localizavam em áreas distantes do núcleo urbano e não havia nos arredores grande densidade, que possibilitou que a ocupação posterior dos setores se dessem simultaneamente.

Tal situação fugiu do controle da URBEL, visto que não existia no órgão, na época, um setor que atuasse na pós-ocupação e fiscalizasse as ações. Ao serem questionados por quê não ampliaram suas casas conforme o estabelecido pelas diretrizes do órgão, os moradores alegavam que não confiavam na estrutura da casa e que "as casas térreas eram mais práticas".

\section{Conclusão}

Pode-se observar que a implantação de conjuntos habitacionais num entorno consolidado envolve um processo complexo, não só do ponto de vista físico como também do social, pois dois grupos com renda, escolaridade, cultura, valores e modos de vida diferentes passam a conviver proximamente.

A intervenção desconsiderou, de início, os princípios ditados pela municipalização da política habitacional, negando a plena participação dos usuários na elaboração do projeto das suas casas. $O$ processo de atendimento das necessidades para os usuários ainda requer maior participação ativa da comunidade, com vistas a identificar cada vez mais as suas aspirações, a exemplo do que ocorre nos projetos individuais.

Cabe, finalmente, uma observação no sentido de valorizar a atuação da pós-ocupação em conjuntos dessa natureza, visto que o processo não termina quando as casas são entregues aos moradores. Pelo contrário, essa continuidade torna-se essencial, posto que as adaptações necessitam de informações e acompanhamento que possibilitem a sua adequação, agora imposta pelo Estatuto da Cidade.

\section{Bibliografia}

MACEDO, Sílvio Soares. Quadro do paisagismo no Brasil. São Paulo: Edição do autor, 1999. (Coleção Quapá).

SANTOS, Carlos Nelson Ferreira dos. Quando a rua vira casa. São Paulo: Projeto, 1985.

SANTOS, Milton. Metamorfoses do espaço construído. 5. ed. São Paulo: Hucitec, 1997.

TEIXEIRA, Maria Cristina Villefort. Espaço projetado e espaço vivido na habitação social: os conjuntos Goiânia e Araguaia em Belo Horizonte. 2004. 256 p. Tese (Doutorado) - Instituto de Pesquisa e Planejamento Urbano e Regional, Universidade do Rio de Janeiro, Rio de Janeiro, 2004. 